\section{Quem sustenta tanto desenvolvimento?}

Who will sustain such development?

\section{Christovam Barcellos ${ }^{1}$}

São Vicente, 1535. Depois de avaliadas, mudas importadas de cana-de-açúcar foram espalhadas por todo o Brasil, vistas como oportunidade para a ocupação da costa brasileira e geração de renda para Portugal. 0 projeto ficou a cargo de nobres portugueses espal hados por capitanias em Pernambuco, Bahia e Rio de Janeiro. Índios capturados em guerras ou aculturados foram usados como os primeiros escravos. Alguns anos mais tarde, optou-se pela importação de milhões de escravos daÁfrica. Seguiram-seséculos deatrocidades, concentração de terra e riqueza e danos ao ambiente.

São Bernardo, 1978. Uma greve de metalúrgicos da Scania inicia uma série de manifestações de operários nos anos de 1979 e 1980, que reivindicam aumento de salário. As indústrias, ainda embaladas pelos resultados financeiros favoráveis decorrentes do "milagre brasileiro" e assustadas diante da mobilização, se dispuseram a negociar. A ditadura militar intervém nos sindicatos e prende seus representantes. As conquistas dos trabalhadores fizeram nascer um novo sindicalismo no país eaumentaram as oportunidades de emprego e renda no ABC. A produção de automóveis, associada a uma classe média em expansão, é vista como uma das princi pais alternati vas de desenvolvimento do Brasil desdea década de cinquenta. Estemesmo automóvel engarrafa as ruas de São Paulo, emite substâncias tóxicas e gases que provocam o aquecimento global.

Unaí, 2004. Três fiscais e um motorista do M inistério do Trabalho foram executados em uma emboscada, após terem investigado denúncias sobre trabal ho escravo em uma das fazendas localizadas no município. Um dos principais suspeitos, Noberto M ânica, é o dono da fazenda, um dos maiores produtores de feijão do país e irmão de um deputado federal. Os suspeitos da chacina ainda não foram julgados. Outros focos de trabalho escravo persistem no país. 0 agronegócio é considerado fator de equilíbrio das contas nacionais e um dos principais geradores de emprego. Também é responsável pela contaminação de águas e solo com agrotóxicos, pelo desemprego sazonal e pela perda de biodiversidade no campo.

É difícil a tarefa de discutir saúde e ambiente em meio à crise econômica mundial. Como ressaltou Henrique Rattner, essa crise tem reduzido a atividade econômica e provocado o desemprego em todo o mundo. Diante de um quadro de incertezas e de mudanças na economia mundial, a tendência do movimento social é, em geral, de retração de expectativas e de aceitação de propostas de redução de salários e flexibilização das condições de trabalho em nome do emprego. Os governos, que vinham seguindo a receita neoliberal de abandono do seu papel de regulador das atividades econômicas, sentiram-se forçados a intervir sobre os mercados, ajudando a recuperar financeiramente empresas, estas mesmas que haviam provocado ou agravado a crise. Parte do dinheiro que socorre as empresas é retirado de projetos sociais, de proteção do ambiente e da saúde.

$\mathrm{O}$ artigo de $\mathrm{H}$ enrique Rattner lembra uma dos bordões do capitalismo: "Embolso privado dos lucros e socialização das perdas". No momento de crise, as empresas recorrem ao Estado como forma de se proteger da falência, que sem dúvida pode causar mais desemprego. $M$ as acabada a crise, 0 emprego voltará a crescer? Depois de reequilibradas as contas, a verba do Estado voltará a ser aplicada em projetos sociais? 0 ambiente ea saúde poderão ser finalmente tomados como prioridades?

Parece que há outra máxima do capitalismo: alardear as crises e esconder os tempos de expansão da economia. Quem vai nos avisar quando esta crise acabar? Sea criseé o momento de dividir os prejuízos, quando será dada a oportunidade de compartilhar as benesses do desenvolvimento? Ninguém pensou em libertar os escravos da cana ou remunerar seu trabalho quando esse produto passou a ser exportado para toda a Europa, gerando excedentes que enriqueceram al guns comerciantes em Portugal e usineiros no Brasil. Nenhuma indústria conclamou seus operários para repartir os lucros obtidos durante o "milagre brasileiro" dos anos setenta. Poucos imaginavam que, atrás da produção recorde de feijão no interior de M inas Gerais, se escondia o trabalho escravo ou semi-escravo. Os melhores momentos de expansão econômica têm sido caracterizados no Brasil pela concentração de renda, desmatamento, assassinato de lideranças do movimento social e contaminação do ambiente. Afinal, segundo os mentores desses projetos, nenhum desses itens deveria poder barrar o desenvolvimento. Do mesmo modo, nos momentos de crise, a concentração de ${ }^{1}$ Fundação O swaldo Cruz, Instituto de Comunicação e
Informação Científica eTecnológica em Saúde. xris@fiocruz.br 
poder eriqueza ea degradação ambiental são apresentados como mal necessário ${ }^{1}$.

Desse modo, a lista de problemas ambientais que é levantada por Rattner pode ser tomada tanto como consequência do desenvolvimento econômico, quanto da sua ausência, decorrente da pobreza. Os níveis deemissão de substâncias tóxicas ou geradoras do efeito estufa não têm precedentes no mundo. A expansão da indústria e 0 aumento do consumo de energia e bens duráveis são apontados como indutores dessas emissões. Por outro lado, persistem os problemas de acesso das populações mais pobres a bens e serviços considerados básicos, como o saneamento, a alimentação, transporte, etc.

A coexistência desses diversos tipos de problemas ambientais deve ser examinada como resultado do desenvolvimento dentro de um quadro de pobreza. Sobre esta sinergia extremamente negativa têm se dedicado inúmeros estudos. Alguns modelos teóricos se apóiam na hi pótese da transição ambiental ${ }^{2}$, segundo a qual as primeiras etapas de desenvolvimento produziriam o consumo intensivo de recursos e emissão de rejeitos para 0 ambiente em grandes proporções. Ainda segundo essa hipótese, com o aumento de renda gerado pelo desenvolvimento, as forças do mercado modificariam a composição da produção e consumo, levando a uma redução de emissões. Os defensores dessa hipótese demonstram que os países com menor nível deatividades industriais possuem boa qualidade ambiental porque ainda não sofreram pressões de produção e consumo. No outro extremo de uma curva em forma de $U$, os países mais industrializados conseguiriam investir no aperfeiçoamento tecnológico einstitucional, fazendo aumentar a qualidade ambiental. No pior estágio de qualidade ambiental estariam os países industrializados de economia periférica, cuja prioridade é o aumento da produção, queérealizada com grande consumo de matéria-prima e geração de rejeitos. Segundo os defensores dessa hipótese, a solução para superar a crise ambiental estaria não na redução ou controle da produção, mas no seu aumento. Por outro lado, todos os países que pretenderem alcançar os níveis de qualidade de vida dos países centrais teriam que passar por um estágio de degradação das condições ambientais, uma espécie de "purgatório" ambiental.

Esta hipótese explica em parteo processo ocorrido em países desenvolvidos. A Europa viveu décadas de degradação ambiental decorrente da Revolução Industrial. As péssimas condições de vida e trabalho dos operários na Inglaterra, as epidemias de cólera em cidades que não possuíam a infraestrutura adequada de saneamento e a alta mortalidade infantil na segunda metade do século XIX são exemplos da degradação ambiental vivida pelos primeiros países que se industrializaram e urbanizaram aceleradamente. A Europa atualmente conta com um desenvolvimento institucional, social etecnológico quepermitea concentração de atividades produtivas que geram renda com menor impacto sobre 0 ambiente e o bem-estar da população. Foram necessárias décadas de desenvolvimento e investimento para superar este quadro e degradação do ambiente e das condiç̧̃̃es de vida. É importante destacar que grande parte dos bens consumidos por estes países é hoje importada de países periféricos, em condições que não podem ser consideradas saudáveis ou sustentáveis. Existe, desta forma, uma exportação de riscos, rejeitos e modelos de produção indesejáveis para países deeconomia periférica, externalizando parte desse processo de transição ambiental ${ }^{3}$. Também é importante lembrar que esse processo não se deu de forma espontânea, por mecanismos de autorregulação dos mercados, mas sim por meio de lutas políticas no campo dos direitos humanos, do trabal ho e emprego, da proteção à saúde, emais recentemente do movimento ecológico. Também os governos nacionais tiveram papel relevante na redução das desigual dades sociais, aumento da expectativa de vida e diminuição da pobreza. Ao contrário do que é apregoado pelo modelo neoliberal, esse processo foi realizado em paralelo ao aumento da cobertura e de gastos com serviços públicos desaúde, departici pação desindicatos, ededemocratização política ${ }^{4}$.

Os exemplos da Europa são ilustrativos de situações decrise ambiental e política vividas no passado. M as não obrigatoriamente temos que seguir a história dos países desenvolvidos. Não precisamos poluir primeiro para limpar depois. Deve-se, antes de tudo, procurar alternativas, voltadas para vocações locais e modelos mais equânimes de desenvolvimento. $N$ esse aspecto, o papel da tecnologia e da informação está, em geral, ausente das análises sobredesenvolvimento, saúdee ambiente. O Brasil não precisa, nem deve, produzir energia como fazia a Inglaterra no começo da Revolução Industrial, com base no carvão. Também não precisa retomar a triste experiência de produção de derivados da cana-de-açúcar do período colonial. Outras tecnologias estão disponíveis e podem ser empregadas para o desenvolvimento. N esse sentido, a posição intermediária do Brasil, entre países de baixa renda preocupados com a sobrevivência e os industrializados com o desenvolvimento voltado para a sustentabilidade", pode permitir dar "sal- 
tos tecnológicos" desde que tenha acesso a tecnologias limpas e que estas escol has se estabeleçam dentro de um debate democrático e ético.

0 que gostaria de ressaltar nesse texto é que esta crise, como as demais crises que ocorreram no capitalismo desde a sua origem, passará. Esta passagem pode ter consequências dramáticas, gerando desemprego, desespero edesilusão. Possivel mente, irá também remodelar a atual estrutura de produção e consumo. Durante a crise, a vida do país e das famílias é alterada de modo significativo, provocando insegurança e perdas materiais. $M$ as as alternativas para a saída da crise estão já sen do projetadas, durante a crise. N esse momento surgem idéias, oportunidades e oportunistas, são identificados novos caminhos e barreiras. Essa passagem podegerar modelos de desenvolvimento ainda mais perversos ou mais humanos, ecológicos e solidários. Os exemplos de projetos de desenvolvimento citados no início deste texto foram gestados em contextos de crise econômica e política: a introdução da cana-de-açúcar, a implantação da indústria automobilística e o agronegócio de grãos.

É difícil recuperar com precisão o momento e os participantes dessas decisões. Os exemplos da cana, indústria e agronegócio mostram um delicado equilíbrio entre Estado, cidadão e empresa. Em alguns momentos, como durante a ditadura militar, o Estado prevaleceu, acima das relações entre empresa e funcionários. No escravismo da cana, 0 Estado legitimou a empresa em detrimento dos semicidadãos, escravos. No caso da chacina de Unaí, como em diversos outros que ocorrem no Brasil contemporâneo, a empresa atentou contra o Estado eseu dever de proteger o cidadão. Essas relações entre Estado, cidadão e empresa, na verdade, são bastante complexas, sendo uma das características da sociedade moderna a interação entre essas partes. A dinâmica econômica cria, ou degenera cidadãos. Os cidadãos e empresas conformam o Estado. Além disso, Estado, cidadão e empresa não constituem unidades. São fragmentados por interesses de classe, de setores da economia e de governo. Um exemplo desses diversos interesses é a coexistência dentro do aparelho de Estado dos defensores do agronegócio e sua expansão e, por outro lado, os que advogam pela agricultura familiar e a reforma agrária. Também as empresas não coincidem em seus interesses, sendo notável a oposição entre capital financeiro ecapital industrial.

Diante dessequadro deconflitos, épreciso pensar e agir. A democracia política, duramente conquistada no Brasil, se ainda não trouxe a plena cidadania e distribuição de riquezas, permite ao menos enxergar essa pluralidade de atores sociais e seus interesses. Os conflitos de interesse permanecerão, mesmo depois de vencida a crise. Os jornais mostram, a cada dia, impasses dos diversos projetos em curso no Brasil: a construção de estradas e hidrelétricas na Amazônia, a expansão das favelas nas metrópoles, a ampliação da cultura da cana-de-açúcar, o aumento da produção de automóveis, entre vários outros. Cada um desses projetos produz ganhadores e perdedores e, por isso, promove a cisão entre grupos e disputas ${ }^{6}$.

Esses conflitos são inevitáveis, e mesmo necessários, para que se estabeleçam bases sociais e ambientais sustentáveis para o desenvolvimento. Como essas disputas emergem em diversos fóruns técnicos e políticos, é imprescindível que o movimento social e os órgãos de governo estejam atentos e preparados, o que demanda a capacitação e fortalecimento das agências de controle ambiental e de vigilância em saúde; a organização e embasamento técnico da sociedade civil; a democratização e difusão de informação sobre projetos de desenvolvimento e seu monitoramento. Qualquer outro caminho, que tente suprimir essas disputas, pode se tornar uma perigosa aventura.

\section{Referências}

1. Acsel rad H. As práticas espaciais e o campo dos conflitos ambientais. In Acselrad $\mathrm{H}$, organizador. Conflitos ambientais no Brasil. Rio de Janeiro: Relume Dumará; 2004. p. 13-35.

2. Kuznets S. Economic Growth and Income Inequality. American Economic Review 1955; 49:1-28.

3. Ansuategi $A$, Perrings $C$. Transboundary externalities in the Environmental Transition Hypothesis. Environmental and Resource Economics 2000; 17:353-373.

4. Navarro V, Shi L. The political context of social inequalities and health. Social Science \& M edicine 2001; 52(3):481-491.

5. U do VE, Jansson PM. Bridging the gaps for global sustainable development: A quantitative analysis. Journal of Environmental M anagement 2009; 90(12):37003707

6. Banerjee SB. Quem sustenta o desenvolvimento de quem? $O$ desenvolvimento sustentável e a reinvenção da natureza. In: Fernandes M, Guerra L, organizadores. Contra-discurso do desenvolvimento sustentável. $2^{\text {a }}$ ed. Belém: UNAM AZ/UFPA-NAEA; 2006. 